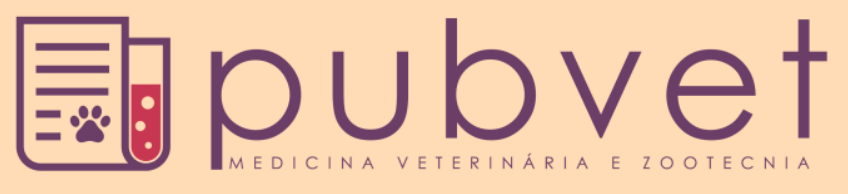

https://doi.org/10.22256/pubvet.v12n3a59.1-9

\title{
Relação homem-animal durante procedimento clínico cirúrgico e pós-operatório em bezerro Holandês Preto e Branco acometido por atresia anal: Relato de Caso
}

\author{
Jackson Barros do Amaral ${ }^{\ominus} 1 *$, Guilherme Trevisan $\bullet 2$ \\ ${ }^{I}$ Médico Veterinário, Pesquisador Científico do Centro de Análises e Pesquisa Tecnológica dos Agronegócios de Bovinos de Leite - Instituto \\ de Zootecnia, Rua Heitor Penteado, 56, CP 60, Nova Odessa - SP, Brasil, CEP 13460-000, \\ ${ }^{2}$ Médico Veterinário, Mestrando da Faculdade de Medicina Veterinária e Zootecnia - FMVZ da Universidade Estadual Paulista - UNESP \\ “Júlio de Mesquita Filho”-Distrito de Rubião Jr., s/n - Botucatu, SP, CEP 18618-970, E-mail guilherme_med.vet@live.com \\ *Autor para correspondência, E-mail: jackson@iz.sp.gov.br
}

\begin{abstract}
RESUMO. Este relato tem o objetivo de descrever a relação homem-animal durante tratamento clínico-cirúrgico e pós-operatório em bezerro holandês acometido por atresia anal e seus possíveis efeitos no bem-estar e no ganho de peso. Atresia anal é uma malformação congênita com oclusões no reto e ânus que ocorre nos animais e no homem. O bem-estar de animais afetados por dor e sofrimento no pós-operatório pode ser influenciado pela relação homem-animal. O animal nasceu em 2016 e após 48 horas constatou-se atresia anal ocasionando dor e sofrimento. Realizou-se cirurgia de emergência com sedação, anestesia local e epidural. A avaliação do bem-estar foi realizada pelos indicadores clínicos, comportamentais, fisiológicos e ganho de peso. No pós-operatório administrou-se antibiótico, anti-inflamatório e polivitamínicos. Após cirurgia observou-se eliminação de gases e mecônio, seguindo com evacuações normais até a alta. A ferida cirúrgica apresentou-se boas condições, no entanto, as fezes apresentavam estrias de sangue, fibrina e tenesmo retal. $\mathrm{O}$ animal normalizou o apetite e apresentou-se ativo e com vigor ao término da cirurgia, explorou o ambiente e utilizou a cama macia nos momentos de descanso e vocalizava antes do aleitamento. Disponibilizou-se feno picado e ração, o que favoreceu alteração na consistência das fezes passando de semipastosa para pastosa. No pós-operatório estabeleceu-se interação homem-animal onde foi possível notar contatos positivos como deixar-se afagar, deixar sugar os dedos, roçar em humanos, evidenciando comportamentos lúdicos como perseguições, brincar, correr, manipulações com objetivos, coices no ar e cabecear. Os indicadores fisiológicos foram normalizados. O ganho de peso foi de $11 \mathrm{~kg}$ em 25 dias. Conclui-se que durante os primeiros 30 dias o tratamento clínico cirúrgico e pós-operatório o animal apresentou boa evolução clínica e que os cuidados humanitários com ações "positivas" na relação homem-animal influenciaram no bem-estar e no ganho de peso.
\end{abstract}

Palavras chave: anomalia anorretal, bem-estar, bovino, cirurgia, malformação congênita

\section{Human-animal relationship during surgical clinical procedure and postoperative calf Holstein Black and White stricken by anal atresia: Case Report}

ABSTRACT. This relate tells the objective of describing human-animal relation during clinical-surgical treatment and postoperative treatment in Holstein calf treated by anal atresia and its possible effects on well-being and gaining weight. Anal atresia is a congenital malformation with occlusions in the challenge and anus that occurs in animals and in human. The well-being of animals afflicted by pain and suffering in the 
postoperative can be influenced by the human-animal relationship. The animal was born in 2016 and after 48 hours, it was found atresia anal grau II, suggestive of pain and suffering. Emergency surgery was performed such as sedation, local anesthesia and epidural. The evaluation of the welfare was performed by clinical, behavioral, and physiological and weight gain hair. In the postoperative antibiotic, anti-inflammatory and polyvitamins were administered. After surgery, elimination of gases and mechanics was observed, following normal evacuations until discharge. The surgical wound showed good conditions; however, the feces presented blood strains, fibrin and rectal tense. The animal normalized the appetite and appeared active and how vigorous at the end of the surgery, explored the environment and used the soft bed at moments of rest and vocalize before breastfeeding. Chopped hay and ration were available, which favored an alteration in the consistency of the feces, going from semipastosa to pasture. In the postoperative, human-animal interaction was established, where it was possible to observe positive accounts such as dropping out, dropping fingers, scratching humans, demonstrating playful behaviors such as persecutions, acrobatics, jump-in, running, manipulations as targets, air and head. The physiological indicators were normalized. The weight gain was $11 \mathrm{~kg}$ in 25 days. It is concluded that during the first 30 days, the surgical and operative clinical treatment the animal presented a good clinical evolution and that humanitarian care as "positive" actions in the human-animal relationship influenced the welfare and gain of weight.

Key words: anorectal anomaly, welfare, bovine, surgery, congenital malformation

\section{Relación hombre-animal durante procedimiento clínico quirúrgico y post operatorio en ternero Holandés Negro y Blanco acometido por atresia anal: Relato de Caso}

RESÚMEN. Este relato tiene el objetivo de describir la relación hombre-animal durante tratamiento clínico-quirúrgico y postoperatorio en ternero holandés acometido por atresia anal y sus posibles efectos en el bienestar y en la ganancia de peso. La atresia anal es una malformación congénita con oclusiones en el recto y ano que ocurre en los animales y en el hombre. El bienestar de animales afectados por dolor y sufrimiento en el postoperatorio puede ser influenciado por la relación hombre-animal. El animal nació en 2016 y después de 48 horas se constató atresia anal, sugestiva de dolor y sufrimiento. Se realizó cirugía de emergencia con sedación, anestesia local y epidural. La evaluación del bienestar fue realizada por los indicadores clínicos, comportamentales, fisiológicos y ganancia de peso. En el postoperatorio se administró antibiótico, antiinflamatorio y polivitamínicos. Después de la cirugía se observó eliminación de gases y meconio, siguiendo con evacuaciones normales hasta el alta. La herida quirúrgica presentó buenas condiciones, sin embargo, las heces presentaban estrías de sangre, fibrina y tenesmo rectal. El animal normalizó el apetito y se presentó activo y con vigor al término de la cirugía, exploró el ambiente y utilizó la cama blanda en los momentos de descanso y vocalizaba antes de la lactancia. Se le suministró heno picado y ración, lo que favoreció la consistencia de las heces pasando de semipastosa para pastosa. En el postoperatorio se estableció interacción hombre-animal donde fue posible notar contactos positivos como dejarse acariciar, succionar los dedos, rozar en humanos, evidenciando comportamientos lúdicos como persecuciones, juegos, corridas, manipulaciones con objetivos, patadas al aire y cabezadas. Los indicadores fisiológicos fueron normalizados. La ganancia de peso fue de $11 \mathrm{~kg}$ en 25 días. Se concluye que durante los primeros 30 días el tratamiento clínico quirúrgico y postoperatorio el animal presentó buena evolución clínica y que los cuidados humanitarios con acciones "positivas" en la relación hombre-animal influenciaron en el bienestar y en la ganancia de peso.

Palabras clave: anomalía anorrectal, bienestar, bovino, cirugía, malformación congénita 


\section{Introdução}

A bovinocultura é um destaque no agronegócio brasileiro. O Brasil possui o segundo maior rebanho efetivo do mundo, com 200 milhões de cabeças (ANUALPEC, 2017). A importância do bem-estar nos sistemas de produção de bovinos leiteiros e a melhoria da qualidade das relações homens-animais durante a criação atende demanda da sociedade e tende a ser incorporada em relações internacionais (Honorato et al., 2012). Os estudos das causas e efeitos da interação de humanos com os animais estão sendo desenvolvidos aos poucos e o conhecimento desta interação tem sido pouco estudado nos bovinos leiteiros, apesar da importância nos dias atuais. Esta interação pode resultar em efeitos positivos ou negativos na produtividade e bem-estar animal (Dawkins, 2017).

A atresia anal é uma anomalia congênita descrita em bovinos (Rizzo et al., 2011), suínos sendo descrita em outras espécies, incluindo equinos, cães e o homem (Tenório et al., 1996). Esta anomalia é caracterizada como uma deformidade da abertura anal e da porção terminal do reto. De acordo com a literatura veterinária é classificada em quatro graus de disgenesia ou agenesia do reto e do ânus, podendo estar associada à fístula reto-vaginal (Rizzo et al., 2011, Carvalho et al., 2012). A malformação congênita do presente relato de caso foi classificada no grau II, de acordo como Rizzo et al. (2011). Esta anomalia é caracterizada pela persistência da membrana anal, dispondo de uma bolsa sem desenvolvimento do ânus. Esta anomalia é diagnosticada pelo exame clínico e exames complementares e está associada a dor e sofrimento, apresentando associação à distensão abdominal, cólica, apatia, tenesmo, gemido e toxemia (Rizzo et al., 2011).

Este relato de caso tem o objetivo de descrever a relação homem-animal durante procedimento clínico-cirúrgico e pós-operatório de um bezerro Holandês acometido por atresia anal e possíveis efeitos no bem-estar e ganho de peso.

\section{Relato de caso}

O bezerro nasceu em junho de 2016 sendo produto de uma vaca com cinco anos de idade, da raça Holandesa Preta e Branca (HPB), submetida à inseminação artificial em tempo fixo (IATF), multípara de segunda parição. $O$ nascimento ocorreu em condições de campo de parto eutócico e período gestacional normal, sem histórico de malformação congênita da parição anterior. Após o nascimento o animal permaneceu com a fêmea no piquete-maternidade durante 24 horas e posteriormente transferido para $\mathrm{o}$ bezerreiro coletivo onde se notou atividade diminuída, inapetência, apatia e permanentemente em decúbito esternal. Após exame clínico geral e específico foi constatado protrusão da região anal, tenesmo retal, arqueamento do dorso, cauda erguida, dilatação abdominal, gemidos, cabeça voltada para o flanco e desconforto.

Procedeu-se avaliação dos parâmetros fisiológicos onde se verificou frequência cardíaca de 152 batimentos por minuto (bpm) e frequência respiratória 56 movimentos por minutos (mpm). Nas alterações circulatórias notaram-se mucosa conjuntival congesta e vasos episclerais injetados sugerindo leve toxemia e leve grau de desidratação. O histórico, a anamnese e o exame clínico permitiram diagnosticar o caso de malformação congênita do tipo atresia anal. Logo em seguida o animal foi transferido para uma baia confortável, livre das intempéries, dispondo de cama de capim, água, ração concentrada, feno e suplemento mineral ad libitum.

\section{Pré-operatório e procedimentos cirúrgicos}

Antes alojar na baia o animal foi pesado cujo peso foi aferido por $32,5 \mathrm{~kg}$. Os procedimentos pré-operatórios foram realizados pela tricotomia da região perianal, sedação, anestesias epidural caudal e local. Procedeu-se a sedação pela administração intramuscular de $0,15 \mathrm{~mL}$ de cloridrato de xilazina a $2 \%$ e em seguida posto em decúbito lateral em mesa com a cauda posicionada dorsalmente para facilitar o acesso cirúrgico, (Figura 1). Após antissepsia com álcool iodado procedeu-se anestesia local com $30 \mathrm{~mL}$ de cloridrato de lidocaína a $2 \%$, sem vasoconstritor, pela aplicação nos tecidos superficiais e profundos da região perianal. Realizou-se tricotomia da região sacral e procedeu-se anestesia epidural caudal no espaço intercoccígeo pela aplicação de $3 \mathrm{~mL}$ de cloridrato de lidocaína a $2 \%$, sem vasoconstritor. Iniciou-se $\mathrm{o}$ procedimento cirúrgico realizando incisão da pele em forma de " $\mathrm{X}$ " seguindo da divulsão cirúrgica da pele, tecido subcutâneo e muscular acessando a ampola retal onde se constatou emissão de gases e presença de mecônio. Procedeu-se a tração da extremidade final da mucosa retal fixando-a na pele e subcutâneo realizando-se sutura em pontos simples separados com fio nylon 3-0 sendo inicialmente fixado em quatro pontos opostos e 
completando a sutura com mais quatro pontos alternados. Fundamentado nos exames clínicos e procedimentos cirúrgicos a malformação congênita foi classificada no grau II o qual se caracteriza pela persistência da membrana anal com o reto posicionado imediatamente cranial ao ânus, dispondo de uma bolsa sem desenvolvimento do mesmo. Ao final da cirurgia procedeu-se antissepsia da ferida cirúrgica utilizando clorexidina degermante. Ao longo do procedimento cirúrgico aplicou-se por via intravenosa um litro de ringer com lactato para controlar a acidose metabólica decorrente do jejum prolongado. Após a cirurgia observou-se eliminação de gases e mecônio, dando início as evacuações e esvaziamento intestinal.

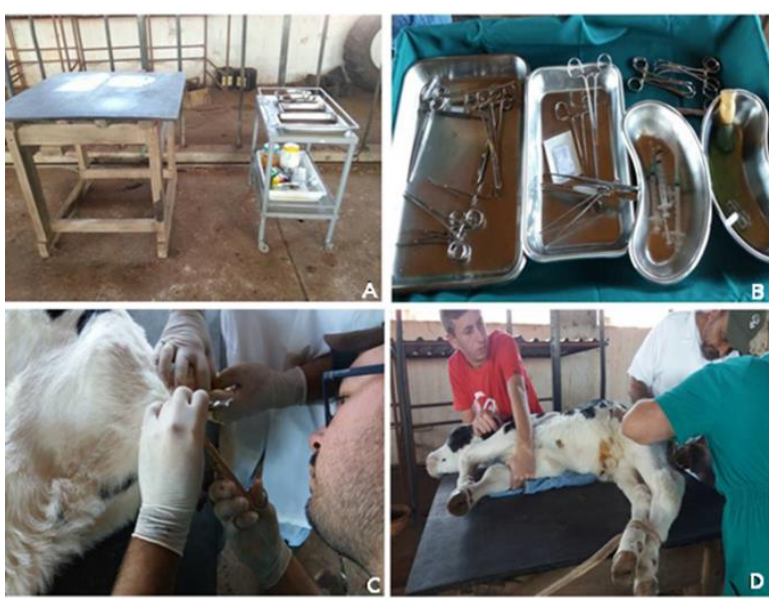

Figura 1. Ambiente cirúrgico e realização da cirurgia - " $A$ " mesa cirúrgica, "B" material cirúrgico, "C" e "D" procedimentos cirúrgicos.

\section{Pós-operatório e tratamento higiênico}

Após a cirurgia o animal foi alojado em baia confortável onde se iniciou o tratamento pósoperatório pela administração de laxativo, utilizando-se enema retal com solução aquosa de $150 \mathrm{~mL}$ de Fleet $^{\circledR}$ Enema, durante os dois primeiros dias, com intervalo de 24 horas. O controle da inflamação e da infecção foram realizados pela administração de $2,2 \mathrm{mg} / \mathrm{kg}$ de flunixina meglumine, por via intramuscular, durante cinco dias consecutivos e $0,022 \mathrm{mg} / \mathrm{kg}$ de cloridrato de oxitetraciclina por via intramuscular, durante 10 dias seguidos. Além do tratamento de suporte utilizando-se $5 \mathrm{~mL}$ de polivitamínico Potenay ${ }^{\circledR}$ Gold B12 por via oral, durante 10 dias consecutivos. No aleitamento artificial utilizou-se de seis litros de leite pré-aquecido a $38^{\circ} \mathrm{C}$, da mãe ministrados em três porções de dois litros ao dia, nos primeiros 10 dias do pós-cirúrgico, e 8 litros ministrados duas porções de quatro litros, duas vezes ao dia, até o trigésimo dia pós-cirúrgico (Figura 2). Nos primeiros dois dias pós-cirúrgicos observou-se que o animal evacuou o mecônio com estrias de sangue e apresentando com tenesmo retal, normalizando, gradativamente, até o $10^{\circ}$ dia pós-cirúrgico. Após este período foi disponibilizado mistura de feno picado e ração concentrada. Esta dieta favoreceu maior consistência das fezes, passando de semipastosa para pastosa.

Durante os primeiros cinco dias realizou-se o tratamento higiênico, duas vezes ao dia, utilizando solução fisiológica de $\mathrm{NaCl}$ 0,9\% e clorexidina degermante. Do quinto ao décimo quinto dia realizou-se a higienização da ferida cirúrgica e do posterior com água corrente e sabão neutro, além da aplicação de pomada Hipoglós ${ }^{\circledR}$ para diminuir a irritação da pele. Efetuou-se a retirada dos pontos cirúrgicos no décimo quinto dia no qual a ferida cirúrgica apresentava-se com boa evolução cicatricial. No período do décimo quinto dia ao vigésimo quinto dia continuou-se com o tratamento higiênico, não sendo observadas alterações na defecação e saúde geral. $\mathrm{O}$ animal apresentou em posição quadrupedal com o dorso arqueado nas primeiras 24 horas do pós-cirúrgico normalizando esta postura após três dias. Não houve complicações do umbigo, tampouco dos sistemas digestivo e respiratório. $\mathrm{O}$ apetite normalizou após a cirurgia permanecendo nesta condição até a alta. Após a cirurgia o animal apresentou-se ativo e com vigor, explorou o ambiente e utilizou-se da cama macia nos momentos de descanso. A vocalização ocorria antes do aleitamento. Disponibilizou-se alimentação complementar com feno picado e concentrado, o que favoreceu alteração gradativa na consistência das fezes passando de semipastosa a pastosa, sendo um indicador fisiológico das defecações. No período pós-operatório estabeleceu-se interação humana com o animal onde foi possível notar contatos positivos como deixar afagar, permitir sugar os dedos, roçar em humanos, evidenciando comportamentos lúdicos como perseguições, brincar, correr, manipular objetos, coices no ar e cabecear. Os indicadores fisiológicos foram normalizados e após a cirurgia constatou-se temperatura normal. O desempenho no ganho de peso foi de $11 \mathrm{~kg}$, avaliado em 25 dias da cirurgia.

\section{Avaliação do bem-estar}

A avaliação do bem-estar foi realizada pelos indicadores comportamentais, fisiológicos, saúde 
e desempenho animal. Nos indicadores comportamentais avaliou-se apetite, atividade, vigor, exploração do ambiente, local de descanso, alimentação, vocalização (horário da ocorrência) e interação homem-animal (contatos "positivos" como afago, deixar sugar os dedos, esfregar-se sobre pessoas e comportamentos lúdicos) (Figuras 2-4). Nos indicadores fisiológicos foram avaliadas a defecação, micção, frequência cardíaca, frequência respiratória, temperatura corporal, coloração das mucosas oral e conjuntival e vasos episclerais. Os indicadores de saúde foram avaliados pelo aspecto da ferida cirúrgica, ocorrência de dor, tenesmo retal, postura, alterações na defecação, condições do umbigo e ocorrência de doenças respiratórias e digestivas. $\mathrm{O}$ desempenho foi avaliado pelas pesagens no dia da cirurgia e no décimo quinto e vigésimo quinto dia pós-cirúrgico.

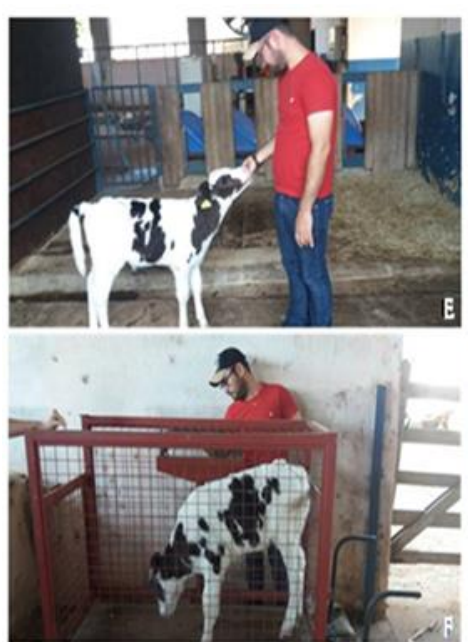

Figura 2. Ações "positivas" comportamentos lúdicos - "E" permitir sugar os ḑaco pesagem e "G" perseguição e acrobacias.

\section{Discussão}

A atresia anal é uma malformação congênita comum em animais e frequentemente acomete a espécie bovina e suína, podendo ser classificada em quatro graus de agenesia do reto e ânus (Rizzo et al., 2011, Carvalho et al., 2012). Esta malformação tem sido observada com menos frequência em bovinos leiteiros podendo nesta espécie estar associada à ausência da cauda, fístula entre o reto e o trato reprodutivo e anormalidades do trato urinário (Steiner, 2004), ocorrendo também na espécie humana (Tenório et al., 1996). A realização de um exame clínico minucioso tem fundamental importância não só para o diagnóstico como para estabelecer o tratamento e prognóstico (Gonçalves \& Barioni, 2000). No presente relato de caso, depois do nascimento do bezerro permaneceu com a fêmea durante 24 horas e após este período transferido ao bezerreiro coletivo no qual se notou que o mesmo se apresentava com atividade diminuída, inapetência, apatia e permanentemente em decúbito esternal. Após inspeção e exame clínico minucioso foram procedidos onde se verificou um quadro clínico com protrusão da região anal, tenesmo retal, arqueamento do dorso, cauda erguida, dilatação abdominal, gemidos, cabeça voltada para o flanco e desconforto. Este exame permitiu a conclusão do diagnóstico de atresia anal grau II, bem como do quadro clínico.

De acordo com Rizzo et al., (2011) e Carvalho et al., (2012) a malformação congênita Grau I é caracterizada por estenose congênita do ânus e o reto normal, no Grau II existe persistência da membrana anal e o reto termina imediatamente cranial ao ânus imperfurado, com uma bolsa cega, sem desenvolvimento do ânus, no Grau III o ânus também está fechado com bolsa de saco cego localizada mais cranialmente, enquanto que no Grau IV ocorre somente em fêmeas onde existe uma comunicação persistente entre o reto e a vagina ou entre o reto e a uretra, formando uma fístula reto-vaginal. No presente relato de caso, após exames clínico-cirúrgicos a malformação congênita foi classificada de acordo com a literatura veterinária como Grau II a qual se caracteriza pela persistência da membrana anal com o reto posicionado imediatamente cranial ao ânus imperfurado, dispondo de uma bolsa sem desenvolvimento do ânus. Portanto, o animal apresentou quadro clínico de dor e sofrimento associados distensão abdominal, cólica, apatia, tenesmo retal, gemidos, inquietude e toxemia, de acordo com o relato descrito por Rizzo et al. (2011) que descreve um caso de malformação congênita do Grau II similar ao presente relato de caso.

Os recursos utilizados na elaboração dos pontos críticos do bem-estar dos bovinos leiteiros têm fundamental importância para elaboração de protocolos de bem-estar fundamentados na realidade brasileira e contribuir para elaboração de uma legislação específica (Bond et al., 2012). No diagnóstico do bem-estar destacam-se os indicadores centrados no animal, já conhecidos e representados pelos indicadores comportamentais, fisiológicos, hormonais e de doenças (Pinheiro \& Brito, 2009, Molento, 2005). No entanto, considera-se a avaliação das emoções como parte principal do diagnóstico do bem-estar animal, 
embora sua avaliação seja subjetiva e difícil (Duncan, 2005). Os problemas de bem-estar enfrentados pelos animais jovens são importantes na bovinocultura leiteira e a separação precoce do bezerro após a parição é crítica do ponto de vista de bem-estar e quando associado a uma doença torna-se uma condição de sofrimento agravante (Bond et al., 2012). No presente relato de caso foi mostrado pelo exame clínico realizado antes cirurgia que houve comprometimento da saúde e do bem-estar tendo em vista que o bezerro se apresentava com atividade diminuída, inapetência, apatia e permanentemente em decúbito esternal. Verificou-se ainda protrusão da região anal, tenesmo retal, escoicear o ventre, arqueamento do dorso, calda erguida, dilatação abdominal, gemidos, cabeça voltada para o flanco, além do desconforto. Este quadro clínico estava associado a alterações dos parâmetros cardíacos e respiratórios com frequência cardíaca de 152 batimentos por minuto (bpm) e frequência respiratória de 56 movimentos por minutos (mpm).

A interação entre homens e animais tem importância fundamental na atualidade podendo adquirir caráter positivo ou negativo, de acordo com o tipo de relação estabelecida (Almeida et al., 2010). Esta interação tem aspecto relevante da produção animal (Dawkins, 2017, Llonch et al., 2015). De acordo com estes autores o bovino pode ser considerado como um indivíduo produtor de alimentos, porém senciente, ou seja, possuem sentimentos, entre eles medo, pânico, angústia, dor sofrimento, os quais não devem ser ignorados no sistema de produção, assim, o bem-estar animal é de grande importância para a comunidade científica e sociedade em geral. Os animais de produção têm relação muito próxima do tratador e vem sendo mantida ao longo do século como uma relação simbiótica (Lensink et al., 2000). Nesta relação os bovinos necessitam do homem para sua manutenção; enquanto que, o homem se beneficia do leite, esterco para adubo, entre outros produtos (Pinheiro \& Brito, 2009).

Com o aumento e intensificação dos sistemas de produção alguns profissionais não reconhecem que a qualidade da interação homem-bovino tenha valor recíproco, demonstrando que estes animais possam ser manejados como produtos de trabalho, sem quaisquer interferências com humanos (Faraco \& Seminotti, 2004), ou quaisquer efeitos de contatos "positivos" ou "negativos" que possam interferir na produtividade (Lensink et al., 2000, Lensink et al., 2001a, Lensink et al., 2001b).
Embora, humanos e bovinos leiteiros interagem diariamente e esta interação tem sido considerada importante e vem demonstrando efeitos notáveis para ambos, podendo resultar em efeitos "negativos" ou "positivos" na produtividade e bem-estar animal (Dawkins, 2017, Llonch et al., 2015).

No presente relato de caso, durante trinta dias consecutivos, observou-se que os contatos com ações "positivas" durante aleitamento, tratamento higiênico e clínico-cirúrgico houve uma interação na relação homem-animal onde o animal desenvolveu comportamento com exibição de atividades lúdicas indicando melhoria no bemestar animal, conforme Figuras 2-4.
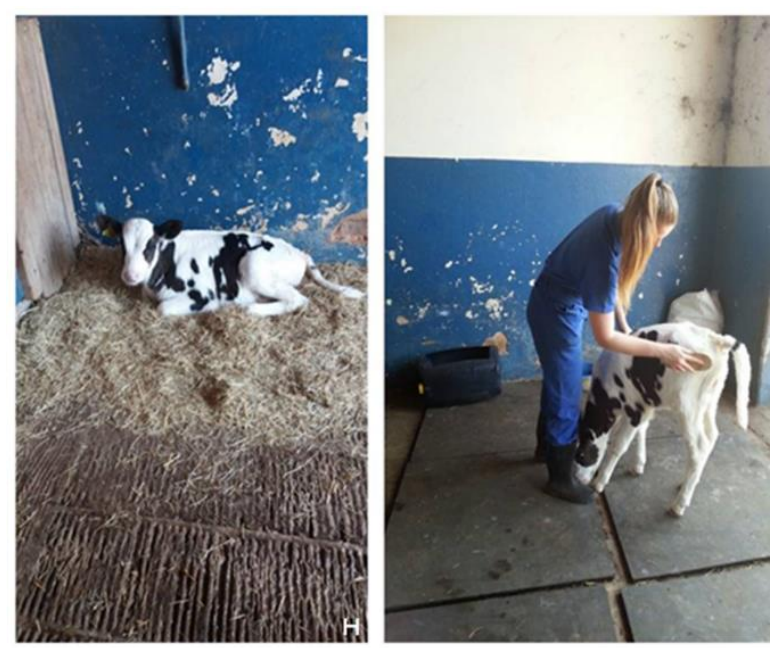

Figura 3. Ações "positivas" e exibição de comportamentos "H" descanso em cama confortável e "I" afago e escovação.

Notou-se que o animal vocalizava somente nos horários que antecedia o aleitamento onde se fornecia seis litros de leite, sendo dois litros pela manhã, dois ao meio-dia e dois pela tarde, durante os primeiros 10 dias, aumentando para oito litros, sendo quatro pela manhã e quatro pela tarde, até o trigésimo dia, sendo que a partir do $10^{\circ}$ dia iniciouse o fornecimento de dieta a base de mistura de feno picado e ração concentrada. No presente relato de caso constatou-se também que no período pós-operatório avaliou-se a interação homem-animal evidenciando comportamentos lúdicos onde se constatou que as ações "positivas" promoveram comportamentos de permitir sugar os dedos de humanos, deixar afagar, exibir acrobacias, manipular objetos, brincar, correr, perseguições, coices no ar e cabecear. Normalizaram-se os indicadores fisiológicos e teve um ganho de peso de $11 \mathrm{~kg}$ durante 25 dias 

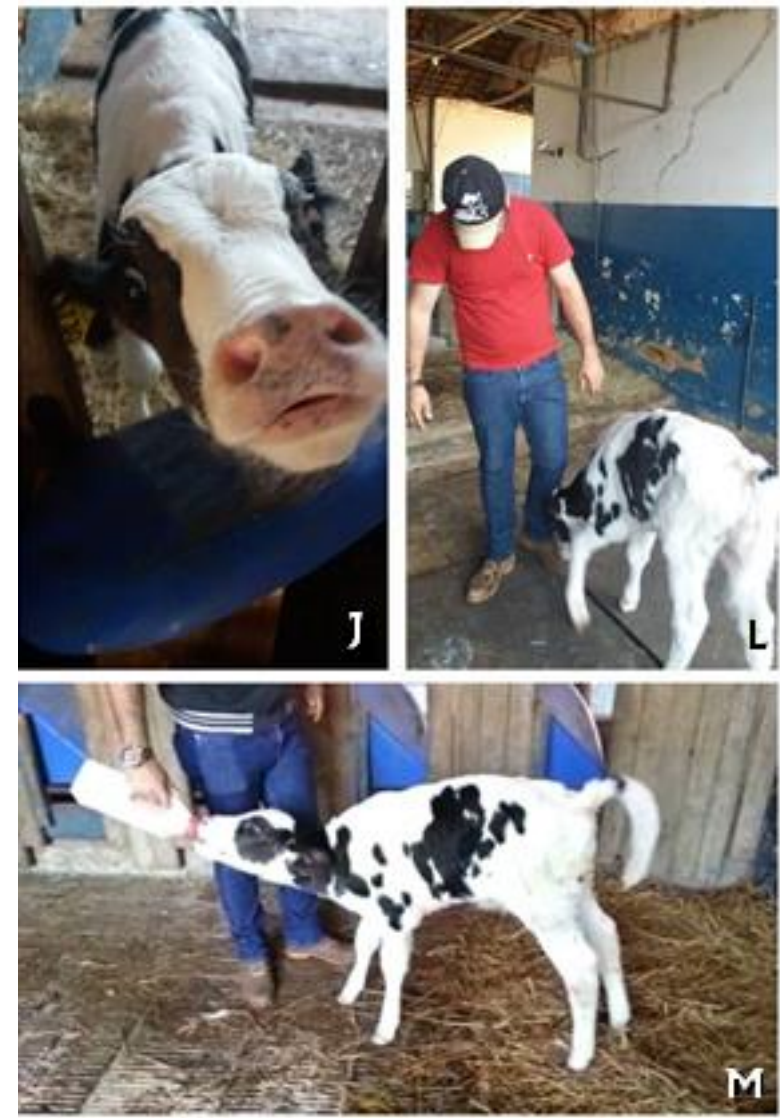

Figura 4. Ações "positivas" com exibição de comportamentos lúdicos - "J" exploração do ambiente, "L" cabecear e "M" amamentação com visualização.

Segundo Lensink et al. (2001a) as interações "positivas" são as que trazem algum benefício ou recompensa, enquanto que as "neutras" não trazem malefícios ou benefícios diretos, já as "negativas" trazem algum mal aos envolvidos e estão presentes na rotina de produção, como exemplo a castração, descorna sem anestesia, injeções, entre outros procedimentos, que podem causar não só comportamento de evitar medo nos animais, como também respostas fisiológicas de estresse. Vacas leiteiras quando são maltratadas por espancamento ou choques elétricos demonstram alterações fisiológicas, com aumento da frequência cardíaca, durante a ordenha, quando o funcionário que maltratou está presente, em comparação com outras vacas não afetadas por maus-tratos (Rushen et al., 1999). Em bovinos, ações "positivas" como interações táteis como tapinhas, carícias na garupa, afago, tom de voz suave registram melhorias no bem-estar animal (Hemsworth et al., 1996, Hemsworth, 2003). Bezerros de raças leiteiras mantidos em sistemas intensivos demonstraram que interações "negativas" como choque elétrico, espancamento ou tapas induziram comportamento de evitar outros animais e foi interpretado como medo, enquanto que interações "positivas" como exemplo afagar, escovar, carícias, entre outras aumentou a interação com o homem (Lensink et al., 2000, Lensink et al., 2001a).

Ações de manejo humanitário durante amamentação de bezerros têm influência no bemestar animal (Molento, 2005, Pinheiro \& Brito, 2009). Segundo este autor bezerros amamentados com visualização da pessoa que afaga e acaricia mostram menos medo do que aqueles amamentados sem visualização, afago e carinho. Assim, quando as ações "positivas" são ignoradas no manejo pode afetar o bem-estar animal. A proximidade da relação homem-animal pode ser avaliada e aferida de acordo com as respostas comportamentais dos animais em relação ao tratador, sendo de fundamental importância para o bem-estar animal (Schütz et al., 2013, Dawkins, 2017). Segundo estes autores bezerras manejadas em bezerreiros coletivos que não recebem contatos "positivos" durante aleitamento são mais agressivas quando comparadas com aquelas que não recebem contatos "positivos" como afago e carícias, as quais são mais dóceis. Quando o fornecimento de leite é combinado com a visualização do tratador o nível de medo é menor do que aqueles animais que são amamentados sem visualização do tratador, ressaltando a importância da relação homem-animal (Jago et al., 1999). Bezerras das raças leiteiras são capazes de diferenciar os tratadores que manejam com ações "positivas", como fornecimento de leite e carícias, daqueles que manejavam ações "negativas" como tapas e empurrões (Passillé et al., 1995). Durante o período de aleitamento bezerras que são manejadas com contatos "positivos" como toques leves, fornecimento de concentrado e feno se tornam animais mais dóceis nos meses subsequentes (Boivin et al., 1992a, Boivin et al., $\underline{1992 b}$ ). O comportamento do responsável pelo tratamento dos animais está diretamente relacionado à sua conduta em relação aos animais (Hemsworth, 2003). Um modelo de interação com reciprocidade na relação homem-animal, na produtividade e no bem-estar animal.

\section{Conclusão}

Nas condições em que o animal foi submetido depois de diagnosticada e tratada a patologia conclui-se que durante os primeiros 30 dias o tratamento clínico cirúrgico e pós-operatório o animal apresentou boa evolução clínica e que os cuidados humanitários com ações "positivas" na relação homem-animal influenciaram no bem- 
estar e no ganho de peso. As questões éticas e os cuidados humanitários dos animais de produção são fundamentais para evitar dor e sofrimentos desnecessários, exigindo a necessidade de avaliações em todos os pontos críticos no sistema de produção de bovinos, sendo a relação homemanimal uma interação de destaque no atual contexto mundial.

\section{Referências Bibliográficas}

Almeida, P. A., Oliveira, J. R. \& Mantovani, M. M. 2010. Determinantes da interação homemanimal. PUBVET, 4, 144.

ANUALPEC. 2017. Anuário da Pecuária Brasileira, 20th edn. Instituto FNP, São Paulo, SP, Brasil.

Boivin, X., Le Neindre, P., Chupin, J. M., Garel, J. P. \& Trillat, G. 1992a. Influence of breed and early management on ease of handling and open-field behaviour of cattle. Applied Animal Behaviour Science, 32, 313-323.

Boivin, X., Neindre, P. L. \& Chupin, J. M. 1992b. Establishment of cattle-human relationships. Applied Animal Behaviour Science, 32, 325335.

Bond, G., B., Almeida, R., Ostrensky, A. \& Molento, C. F. M. 2012. Métodos e pontos críticos de bem-estar de bovinos leiteiros. Ciência Rural, 42, 1286-1293.

Carvalho, Y. N. T., Branco, M. A. C., Mota, H. C. M., Evangelista, L. S. M., Silva, S. V. \& Feitosa Júnior, F. S. 2012. Atresia anal associada à fístula reto-vaginal em bezerra: uma revisão. PUBVET, 6, 1-6.

Dawkins, M. S. 2017. Animal welfare and efficient farming: is conflict inevitable? Animal Production Science, 57, 201-208.

Duncan, I. J. H. 2005. Sciense-based assessment of animal welfare: farm animals. Revue Scientific et Technique Office et International des Epizooties, 2, 483-492.

Faraco, C. B. \& Seminotti, N. 2004. A relação homem-animal e a prática veterinária. Revista CFMV , 10, 57-62.

Gonçalves, R. C. \& Barioni, G. 2000. Exame clínico do aparelho respiratório de bezerros. Revista de Educação Continuada do CRMV$S P, 3,4-13$.

Hemsworth, P. H. 2003. Human-animal interactions in livestock production. Applied Animal Behaviour Science, 81, 185-198.
Hemsworth, P. H., Price, E. O. \& Borgwardt, R. 1996. Behavioural responses of domestic pigs and cattle to humans and novel stimuli. Applied Animal Behaviour Science, 50, 43-56.

Honorato, L. A., Hötzel, M. J., Gomes, C. C. M., Silveira, I. D. B. \& Machado-Filho, L. C. P. 2012. Particularidade relevante da interação humana-animal para o bem-estar e produtividade de vacas leiteiras. Ciência Rural, 42, 332-339.

Jago, J. G., Krohn, C. C. \& Matthews, L. R. 1999. The influence of feeding and handling on the development of the human-animal interactions in young cattle. Applied Animal Behaviour Science, 62, 137-151.

Lensink, B., Fernandez, X., Boivin, X., Pradel, P., Le Neindre, P. \& Veissier, I. 2000. The impact of gentle contacts on ease of handling, welfare, and growth of calves and on quality of veal meat. Journal of Animal Science, 78, 12191226.

Lensink, B. J., Raussi, S., Boivin, X., Pyykkönen, M. \& Veissier, I. 2001a. Reactions of calves to handling depend on housing condition and previous experience with humans. Applied Animal Behaviour Science, 70, 187-199.

Lensink, B. J., Veissier, I. \& Florand, L. 2001b. The farmer's influence on calves' behaviour, health and production of a veal unit. Animal Science, 72, 105-117.

Llonch, P., King, E. M., Clarke, K. A., Downes, J. M. \& Green, L. E. 2015. A systematic review of animal based indicators of sheep welfare on farm, at market and during transport, and qualitative appraisal of their validity and feasibility for use in UK abattoirs. The Veterinary Journal, 206, 289-297.

Molento, C. F. M. 2005. Bem-estar e produção animal: Aspectos econômicos - Revisão. Archives of Veterinary Science, 10, 1-11.

Passillé, A. M., Rushen, J. \& Martin, F. 1995. Interpreting the behaviour of calves in an openfield test: a factor analysis. Applied Animal Behaviour Science, 45, 201-213.

Pinheiro, A. A. \& Brito, F. I. 2009. Bem-estar e produção animal. EMBRAPA, Sobral.

Rizzo, H., Jesus, H. J., Ribeiro, R. M., Mero, H. C., Souza, C. H. R., Rocha, F. A. B., Moreira Neto, J. T. M., Santos, L. A., A., Santana, T. O., Guimarães, V. A. A. \& Guimarães, M. A. 2011. Tratamento clínico cirúrgico de atresia 
anal em bezerro. Veterinária e Zootecnia, 18, 478-481.

Rushen, J., Passillé, A. M. B. \& Munksgaard, L. 1999. Fear of people by cows and effects on milk yield, behavior and heart rate at milking. Journal of Dairy Science, 82, 720-727.

Schütz, K. E., Cox, N. R., Macdonald, K. A., Roche, J. R., Verkerk, G. A., Rogers, A. R., Tucker, C. B., Matthews, L. R., Meier, S. \& Webster, J. R. 2013. Behavioral and physiological effects of a short-term feed restriction in lactating dairy cattle with different body condition scores at calving. Journal of Dairy Science, 96, 4465-4476.
Steiner, A. 2004. Surgery of the colon. In: Fubini, S. \& Ducharme, N. (eds.) Farm animal surgery. Elservier Sounders, Saint Louis, Missouri, USA.

Tenório, L., A., Araújo Filho, W. F. \& Normande Filho, H. V. 1996. Atresia retal. Jornal de Pediatria, 72, 181-183.

Article History:

Received 22 November 2017

Accepted 12 January 2018

Available online 26 February 2018

License information: This is an open-access article distributed under the terms of the Creative Commons Attribution License 4.0, which permits unrestricted use, distribution, and reproduction in any medium, provided the original work is properly cite 